\title{
Project Stratagems for a Nonlinear Vector Controller Fed BLDC Motor
}

\author{
T.V. Subhashini, K. Alice Mary, K. Ravindra
}

\begin{abstract}
Brushless DC (BLDC) motors are becoming an engaging alternative to $D C$ and Induction motors. Various types of control strategies like direct vector control and indirect vector controls are illustrated for variable speed Alternating current drives. When those control strategies are applied to the proposed drive, there are certain drawbacks like instability, sensitive to parameter variations, etc. In this work, in order to get rid of the above difficulties, a design methodology is proposed in the closed loop control of BLDC drive, in which there is an instinctive flexibility to produce the required torque for various possible set of currents. Using this methodology we can attain better control over the drive. A suitable nonlinear and a robust controller makes the drive robust, which in turn makes the system insensitive to the parameter variations and increases the degree of stability. Robust control is a technique, which can precisely deals with uncertainty. These control techniques are used to accomplish robust performance and stability in the existence of bounded modeling errors. This paper gives more information regarding the design features of BLDC motor using MATLAB software.
\end{abstract}

Keywords: Brushless DC Motor, Feedback linearization technique, Pole placement technique, Internal power factor angle control, Torque or load angle control.

\section{INTRODUCTION}

A BLDC motor resembles like a DC motor according to mathematical modeling aspect. These motors are electronically commutated motors fed by the DC supply. Each phase of this motor is supplied by means of inverter or switching mode power supply through a closed loop controlling technique. The absence of slip rings leads to improving the efficiency, reliability and power factor [1]. The position feedback requirement for a BLDC motor is much simpler compared to PMSM as it requires ceaseless and momentary absolute rotor position. In a BLDC motor the conventional method of position estimation involves only the six active voltage vectors with which it is modeled resulting saving in the major cost in the feedback sensor [2]. For a three phase BLDC motor, due to its construction and design, the flux distribution is trapezoidal. The voltage equations are incorporated with trapezoidal induced $\operatorname{emfse}_{\mathrm{a}}{ }^{\mathrm{s}}, \mathrm{e}_{\mathrm{b}}{ }^{\mathrm{s}}$, and $\mathrm{e}_{\mathrm{c}}{ }_{\mathrm{c}}^{\mathrm{s}}$, which are the functions of $\theta_{\mathrm{r}}[3]$, apart from the usual voltage drops. As the phase voltage equation of BLDC motor is identical to that of DC motor, this machine is named as BLDC machine.

Revised Manuscript Received on August 20, 2019.

Mrs. T. V. Subhashini*, EEE Department, ANITS, Visakhapatnam, Andhra Pradesh, India.

Dr. K. Alice Mary, EEE Department, Gudlavalleru Engineering college, Gudiwada, Andhra Pradesh, India.

Dr. K. Ravindra, EEE Department, JNTU Kakinada, Kakinada, Andhra Pradesh, India.
The control strategy for BLDC motor is simple and the nonlinearity of this motor is initially linearized by a suitable feedback linearization technique. Once the model is linearized, then the linear control aspects are applied to get the robust dynamic performance of the system. The control strategy is designed using current and speed control loops. Based on the required load torque the speed controller generates reference torque $\mathrm{T}_{\text {estar }}$. The reference stator currents in rotor reference frame arei $i_{\text {dstar }}$ and $i_{\text {qstar }}$ [4] can be generated by reference current generator.

A given torque may be accomplished by discretionary selection of the torque angle (load angle) $\delta$ and the internal power factor angle $\psi$ of theBLDC motor. These angles can be suitably chosen to attain various control strategies like field oriented control (FOC), etc. Using Clarke and Park transformations the motor model should be transformed from a three phase to two phase [5].

The block diagram of BLDC drivewith proposed control strategy is as shown in Fig. 1.

DC Supply

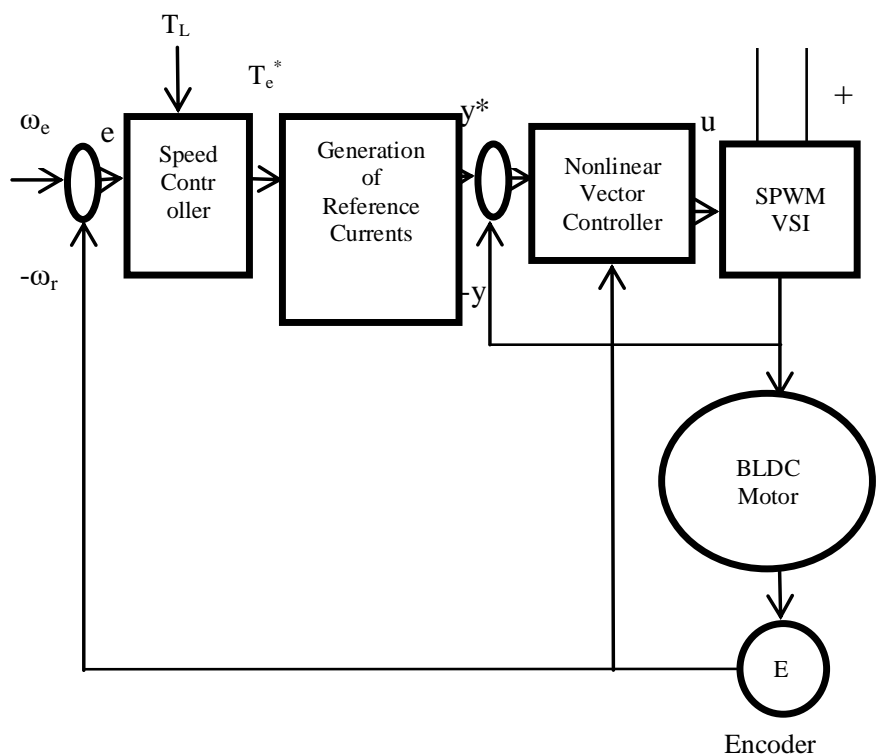

Fig. 1. Block Diagram of BLDC drive

\section{MATHEMATICAL MODELING OF BLDC MOTOR}

To attain the finest performance of the drive, it is necessary to go for mathematical modeling equations of the motor. These equations are developed by neglecting saturation, space harmonics,hysteresis and eddy current losses and also by assuming the trapezoidal induced emfs. 
The equations of stator phase voltages of a BLDC motor in rotor rotating reference frame [6] are

$$
\begin{aligned}
& v_{q}^{s}=\left(v_{q}^{s 1}-\omega_{r} \psi-e_{a q}^{s}\right)=r_{a s} i_{q}^{s}+l_{q}^{s} p i_{q}^{s}+l_{a}^{q} p i_{q}^{r}+\omega_{r} l_{d}^{s} i_{d}^{s}+\omega_{r} l_{d}^{a} i_{d}^{r}(1) \\
& v_{d}^{s}=\left(v_{d}^{s 1}-e_{a d}^{s}\right)=r_{a s} i_{d}^{s}+l_{d}^{s} p i_{d}^{s}+l_{d}^{a} p i_{d}^{r}-\omega_{r} l_{q}^{s} i_{q}^{s}-\omega_{r} l_{q}^{a} i_{q}^{r}(2) \\
& v_{q}^{r}=r_{a q}^{r} i_{q}^{r}+l_{q}^{r} p i_{q}^{r}+l_{q}^{a} p i_{q}^{s}(3) \\
& v_{d}^{r}=r_{a d}^{r} i_{d}^{r}+l_{d}^{r} p i_{d}^{r}+l_{d}^{a} p i_{d}^{s}(4)
\end{aligned}
$$

Where $\Psi=l_{d}^{a} i_{f}^{r}$, which is air gap flux linkage.

Equations (1) and (2) represent stator phase voltages in d$\mathrm{q}$ axes in the rotor reference frame. Equations (3) and (4) represent damper winding voltages in the rotor reference frame.

The developed electric torque is

$T_{e}=\frac{3 P}{4}\left[\left(l_{d}^{a}-l_{q}^{a}\right) i_{q}^{s} i_{d}^{s}+l_{d}^{a} i_{q}^{s} i_{d}^{r}-l_{q}^{a} i_{q}^{r} i_{d}^{s}+\psi i_{q}^{s}\right](5)$

\section{DESIGN OF SPEED CONTROLLER}

The closed loop control structure is shown in Fig. 1. A PI controller is used as a speed controller. The gain constants of PI controller are given as

$$
\begin{aligned}
& k_{i}=\frac{I}{2} \omega_{n}^{2}(6) \\
& k_{p}=I \zeta \omega_{n}-\frac{D}{2}(7)
\end{aligned}
$$

By assuming the proper values of damping ratio $\zeta$, undamped natural frequency $\omega_{n}$ and by using the assigned values of moment of inertia $I$, friction coefficient $D$, these gain constants $k_{p}$ and $k_{i}$ can be determined.

\section{GENERATION OF REFERENCE CURRENTS}

From(5), the generated torque of BLDC motor is a function of the state variables i.e., the stator currents, and damper winding currents, which leads to nonlinear. Due to this nonlinearity, there are several combinations of these currents to produce the required electrical torque. Hence, there is a highresilience in the selection of reference currents.

The Phasor diagram of a BLDC motor is shown in Fig. 2.

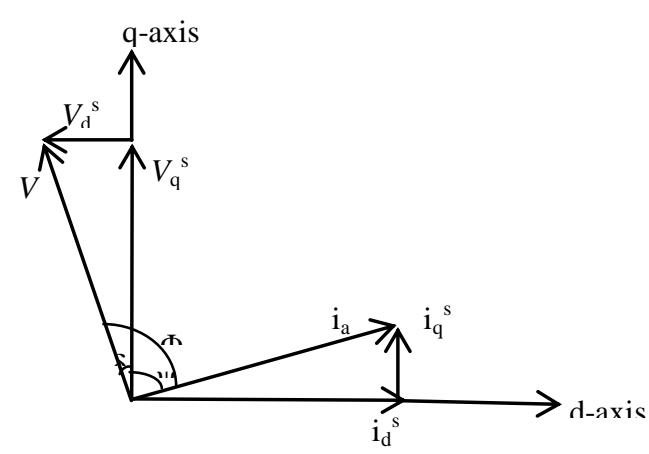

Fig. 2. Phasor Diagram of BLDC motor

There are three conditions to obtain the unique solution for these reference currents. One is with an arbitrary setting of $\psi$, second is with the arbitrary setting of $\delta$ and the third is with all real values of the reference currents [7].

From Fig. 2, we can write

$\tan \delta=\frac{-v_{d}^{s}}{v_{q}^{s}}(8)$

Under steady state conditions, by substituting $v_{q}^{s}$ and $v_{d}^{s}$ values in (8), we get

$\tan \delta=\frac{-\left(r_{a s} i_{d}^{s}-\omega_{r} l_{q}^{s} i_{q}^{s}+e_{a d}^{s}\right)}{r_{a s} i_{q}^{s}+\omega_{r} r_{d}^{s} i_{d}^{s}+\omega_{r} \Psi+e_{a q}^{s}}$

With specification of $\psi$, we can write

$\tan \psi=\frac{i_{d}^{s}}{i_{q}^{s}}(10)$

By combining (8), (9) and (10), we get

$$
\begin{aligned}
& i_{\text {qstar }}=\frac{T_{\text {estar }}}{3\left[\left(l_{a}{ }^{d}-l_{a}^{q}\right) i_{d s t a r}+\Psi\right]^{(11)}} \\
& i_{\text {dstar }}=\frac{-b \pm \sqrt{b^{2}-4 a c}}{2 a} \text { (12) } \\
& a=3\left(l_{a}{ }^{d}-l_{a}{ }^{q}\right)\left(-r_{a s}-\omega_{r} l_{d}^{s} \tan \delta\right) \\
& b=-3\left(l_{a}{ }^{d}-l_{a}{ }^{q}\right)\left(e_{a d}{ }^{s}+\omega_{r} \Psi+e_{a q}^{s}\right) \tan \delta+3 \psi\left(-r_{a s}-\omega_{r} l_{d}^{s} \tan \delta\right) \\
& c=-3 \Psi e_{a d}^{s}-3 \Psi^{2} \omega_{r} \tan \delta-3 e_{a q}^{s} \Psi \tan \delta-\left(r_{a s} \tan \delta-\omega_{r} l_{q}^{s}\right) T_{\text {estar }}
\end{aligned}
$$

Due to permanent magnet rotor, BLDC motor rotor has constant current which leads to constant flux linkage, $\Psi$. There are three different sets of equations to derive the reference currents, one is with specific value of $\delta$, second is with specific value of $\psi$ and the third is field oriented (FO) case. By varying $\delta$ and $\psi$ individually within a particular range the performance characteristics of the drive can be improved.

\section{NONLINEAR CONTROLLER}

For a mathematical model of a multivariable system the output variables are properly regulated to the set points using state feedback control. The model is initially linearized, then linear control law is applied to the system with a gain matrix $K$ [7]. Along with this, to have perfect stability of the system a state feedback control is used [8]. The control signal ' $u$ ' can be written as

$$
\dot{u}=K Z=\left[\begin{array}{ll}
K_{b}^{1} & K_{i}^{1}
\end{array}\right]\left[\begin{array}{c}
\dot{x} \\
y-y_{r}
\end{array}\right] \text { (14) }
$$

Where, $K_{b}{ }^{1}$ and $K_{i}{ }^{1}$ are subparts of $K$.

$$
u=K_{b}^{1} x+K_{i}^{1} \int_{0}^{t}\left(y-y_{r}\right) d t(15)
$$

From (15), it can be observed that, the integral of output error (IOE) can make the drive robust using closed loop controller from the mathematical modeling fallibilities, disturbances and disorders. 


\section{GUIDELINE STRATEGIES}

The design strategy for the BLDC motor is constructedusing (1), (2), (3), (4) and (5) by allowing one to choose $\delta$ or $\psi$ or by selecting both independently to get a requisite control objective likerequired power factor, flux weakening operations and FOC. The ratings of the machine and the values of the parameters are given in the appendix.

From the design guidelines, fordifferent values of $\delta$ at a particular value of constant flux $\Psi$, the armature phase current is, $i_{\text {phase }}=\sqrt{\frac{\left(i_{\text {dstar }}^{2}+i_{\text {qstar }}^{2}\right)}{2}}$. These characteristics give us the satisfactory guidelines for different power factors starting from lagging through unity to leading values. This gives us a clear picture about the practical working range of the motor for different values of the power factors in order to proceed for real time implementation.

\section{RESULTS AND DISCUSSIONS}

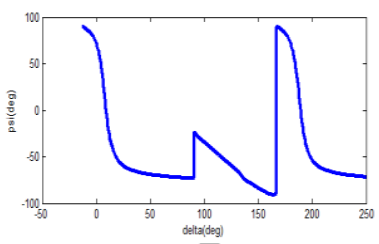

$a$
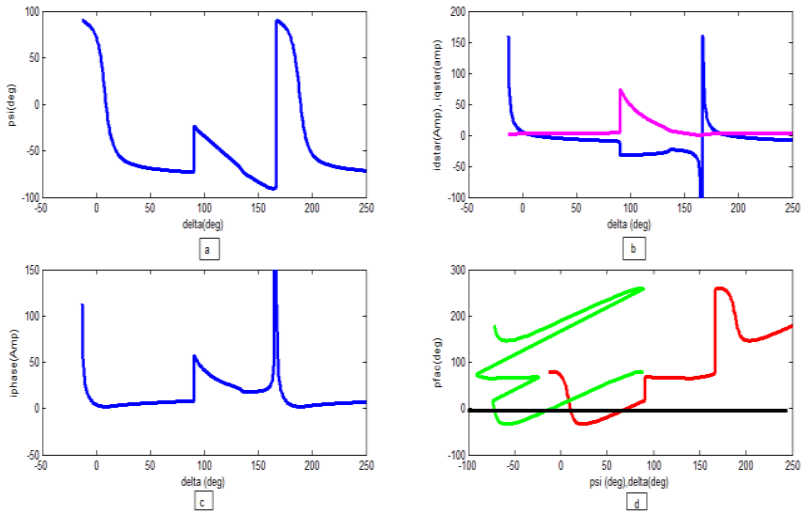

Fig. 3. Design guidelines of BLDC motor with $\delta$ (torque angle) variation, a) $\delta$ vs psi (internal power factor angle), b)

$\delta$ vsi $_{\text {dstar }}$ (blue) and $\mathrm{i}_{\mathrm{qstar}}$ (pink), c) $\delta$ vs Armature phase current, d) $\delta$ (red) and psi (green) vs Power factor angle, unity power factor line (black)
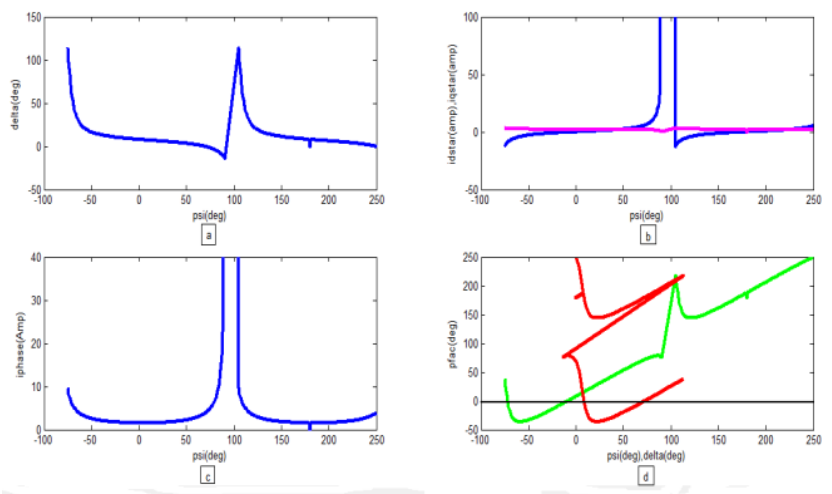

Fig. 4. Design guidelines of BLDC motor with $\psi$ variation, a) $\psi$ vs $\delta$, b) $\psi v v_{\text {vif }}$ dstar $\left(\right.$ blue) and $\mathrm{i}_{\text {qstar }}$ (pink), c) $\psi$ vsi $i_{\text {phase }}$, d) $\delta$ (red) and psi (green) vs Power factor angle, unity power factor line (black)
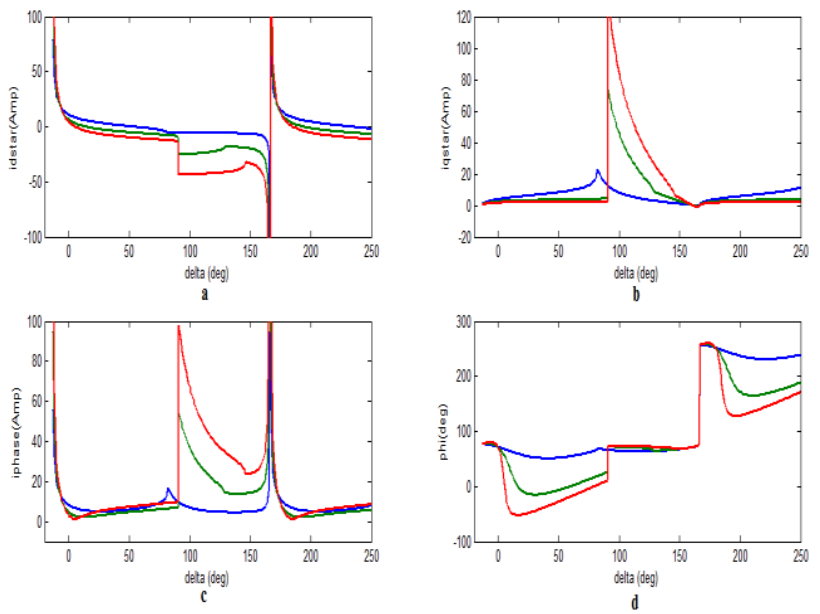

Fig. 5. Family of curves of Design guidelines of BLDC motor with $\delta$ variation for different Fluxes, a) $\delta v_{\text {vsi }}{ }_{\text {dstar }}$, b) $\delta$ $\mathrm{vsi}_{\mathrm{qstar}}$, c) $\delta$ vs Armature phase current, d) $\delta$ vs Power factor angle. Ascending values of flux: Blue $<$ green $<$ red
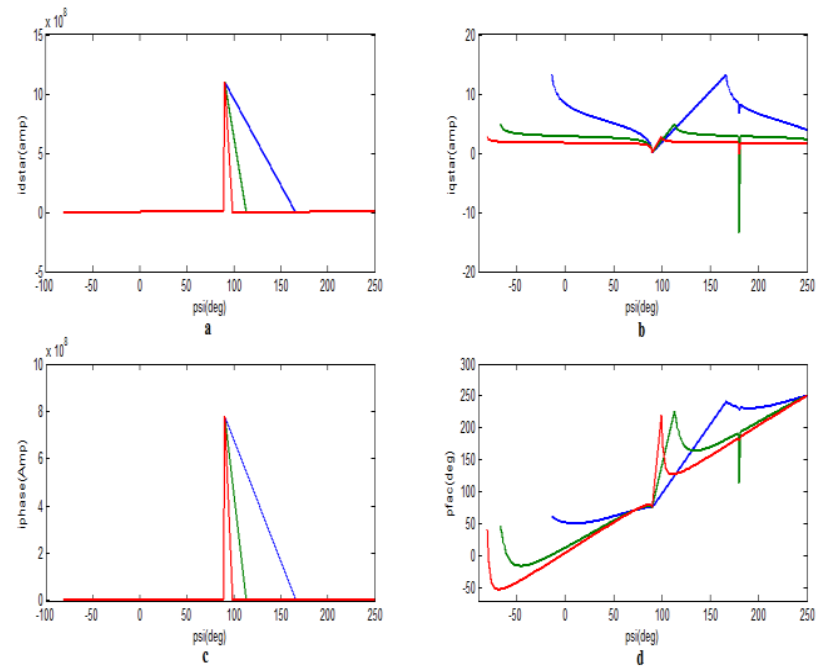

Fig. 6. Family of curves of Design guidelines of BLDC motor with $\psi$ variation for different Fluxes, a) $\psi v v_{\text {distar }}$, b) $\psi \mathrm{vsi}_{\mathrm{qstar}}$, c) $\psi \mathrm{vs}$ Armature phase current, d) $\psi \mathrm{vs}$ Power factor angle. Ascending values of flux: Blue $<$ green $<$ red

The mutual flux linkage $\left(\lambda_{\mathrm{m}}\right)$ of BLDC motor is the resultant of stator and rotor flux linkages [9].

$\lambda_{m}=\sqrt{\left(\lambda_{a f}+l_{d}^{a} i_{d s t a r}\right)^{2}+\left(l_{q}^{a} i_{q s t a r}\right)^{2}}$

Where, $\lambda_{a f}$ is the rotor flux linkage linking with the stator,

$l_{d}^{a}$ is the inductance of stator d-axis winding and $l_{d}^{a}$ is the inductance of stator q-axis winding in rotor reference frame. $\mathrm{T}_{\mathrm{e}}$ in terms of rotor flux linkages can be written as [10],

$T_{e}=\frac{3}{2} \frac{P}{2}\left[\left(l_{d}^{s}-l_{q}^{s}\right)\left(\frac{1}{2}\right) i_{\text {phase }}^{2} \sin 2 \delta+\lambda_{\text {af }} i_{\text {phase }} \sin \delta\right]$

The design guidelines of BLDC motor with torque angle $\delta$ variation is shown in Fig. 3. From Fig. 3.a, for the values of negative $\delta$ ie., from $-13^{\circ}$ to $0^{\circ}$ with respect to (17) the machine works as a generator. From Fig. 3.b, for $\delta$ increasing from $0^{0}$ upto $5^{0}, \mathrm{i}_{\text {dstar }}$ decreases and at $\delta=5^{0}, \mathrm{i}_{\mathrm{dstar}}$ and $\mathrm{i}_{\mathrm{qstar}}$ are equal to a value of $2.012 \mathrm{~A}$ which indicates a lagging power factor as shown in

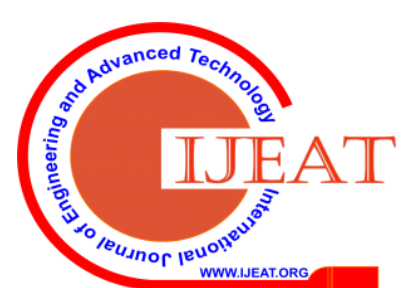


Fig. 3.d. At $\delta=9^{0}, i_{\text {dstar }}$ becomes zero which represents FO (field oriented) case for which also the power factor is lagging which is depicted in Fig. 3.d, at this point the armature phase current is found to be minimum with a value of 1.529 A (Fig. 4.c). The armature phase current $i_{\text {phase }}$ is governed by the $\mathrm{i}_{\text {dstar }}$ for $\delta<9^{0}, \mathrm{i}_{\text {phase }}$ is governed by the $\mathrm{i}_{\mathrm{qstar}}$ for $\delta>9^{0}$ and unity power factor occurs at $\delta=10.2^{0}$ and at $72^{0}$. From Fig. 3.b, it is observed that at $\delta=90^{\circ}$ the torque is controlled by the stator q-axis current, which is identical to that of separately excited armature controlled DC motor. At $\delta=90^{\circ}$ to $185^{\circ}$, there is a sharp increase and decrease of $i_{\text {dstar }}$ and $\mathrm{i}_{\text {qstar }}$ to very high values so that the motor may not work. Care has to be taken that the motor should not be operated during this region. Beyond $\delta=185^{\circ}$ the motor regains to its dynamic performance. From Fig. 3.d, it is observed that the two plots are counterpart to each other.

The design guidelines of BLDC motor with internal power factor angle $\psi$ variation is shown in Fig. 4. From Fig. 4.a, for the negative values of $\psi$ from $-75^{0}$ to $-72^{0}$ the motor is working with lagging power factors. For $-72^{0}<\psi<-9^{0}$ the motor is working with leading power factors and Unity power factor occurs at $\psi=-72^{0}$ and secondly at $\psi=-9^{0}$ which are clearly depicted in Fig. 4.d. From Fig. 4.b, At $\psi=0^{0}$, $\mathrm{i}_{\mathrm{dstar}}=0^{0}$ represents $\mathrm{FO}$ case and at which the motor always operates at lagging power factor angle equal to $7.864^{\circ}$ and it can also be observed that at $\psi=42^{0}, \mathrm{i}_{\mathrm{dstar}}$ and $\mathrm{i}_{\text {qstar }}$ are equal to a value of $2.054 \mathrm{~A}$ and the power factor angle is $46.19^{\circ}$ lagging which is depicted in Fig. 4.d. For $\psi>42^{0}, \mathrm{i}_{\text {dstar }}$ will increase and $i_{\mathrm{qstar}}$ will decrease. From Fig. 4.c, it is observed that for $\psi>42^{0}$ the armature phase current is totally governed

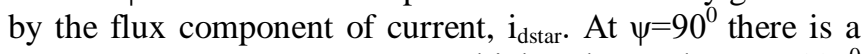
sharp increase in $i_{\text {dstar }}$ to a very high value and at $\psi=105^{\circ}$ there is a sharp decrease in $i_{\text {dstar }}$ to a low value $-13.11^{0}$. During this region i.e., $\psi=90^{\circ}$ to $105^{\circ}$ the motor may not work. Care has to be taken that the motor should not be operated during

Table-I: Design Values of BLDC Motor

\begin{tabular}{|c|c|c|c|c|c|c|c|c|}
\hline \multicolumn{2}{|c|}{ Specification } & $\delta(\mathrm{deg})$ & $\psi(\mathrm{deg})$ & $\varphi(\mathrm{deg})$ & $\operatorname{Cos} \varphi$ & $\mathrm{i}_{\mathrm{dstar}}(\mathrm{amp})$ & $\mathrm{i}_{\mathrm{gstar}}(\mathrm{amp})$ & $\mathrm{i}_{\text {phase }}(\mathrm{amp})$ \\
\hline \multirow{2}{*}{ max. lag } & $\delta$ variation & -8 & $86.72^{*}$ & 78.72 & 0.19 & 22.7 & 1.301 & 16.09 \\
\hline & $\psi$ variation & $165.4^{*}$ & -87 & 78.4 & 0.2 & 24.19 & 1.268 & 17.13 \\
\hline \multirow{2}{*}{$\min$. lag } & $\delta$ variation & 10 & $-8.579 *$ & 1.421 & 0.99 & -0.33 & 2.186 & 1.563 \\
\hline & $\psi$ variation & $8.504^{*}$ & -7 & 1.504 & 0.999 & -0.268 & 2.182 & 1.555 \\
\hline \multirow[b]{2}{*}{ Upf } & $\delta$ variation & 10.2 & $-10.2^{*}$ & 0 & 1 & -0.4 & 2.19 & 1.58 \\
\hline & $\psi$ variation & 9* & -9 & 0 & 1 & -0.346 & 2.187 & 1.566 \\
\hline \multirow{2}{*}{$\begin{array}{c}\text { min. } \\
\text { lead }\end{array}$} & $\delta$ variation & 11 & $-17.58^{*}$ & -6.579 & 0.993 & -0.7 & 2.21 & 1.639 \\
\hline & $\psi$ variation & 49.207 * & -59 & -9.793 & 0.985 & -8.308 & 2.861 & 6.213 \\
\hline \multirow{2}{*}{$\begin{array}{l}\text { max. } \\
\text { lead }\end{array}$} & $\delta$ variation & 24 & $-58.33^{*}$ & -34.33 & 0.825 & -3.97 & 2.45 & 3.3 \\
\hline & $\psi$ variation & $34.79 *$ & -71 & -36.21 & 0.806 & -4.09 & 2.46 & 3.377 \\
\hline FOC & $\begin{array}{l}- \\
-\end{array}$ & 7.864 & 0 & 7.864 & 0.99 & 0 & 2.165 & 1.531 \\
\hline
\end{tabular}

Here $*$ indicates the actual value

this region. Beyond $\psi=105^{\circ}$ the motor regains to its dynamic performance. From Fig. 4.d, it is also observed that the two plots are counterpart to each other. The design values of the proposed BLDC motor are shown in (Table 1), which are taken from Fig. 3 and 4. The family of curves of Design guidelines of BLDC motor with $\delta$ variation for different Fluxes is shown in Fig. 5. From Fig. 5, it is observed that the non-operating region as we have already discussed in Fig. 3, remains same for any value of flux. From Fig. 5.a, 5.b with the increase of flux the currents $i_{\text {dstar }}$ and $i_{\text {qstar }}$ are increasing. From Fig. 5.c, the $i_{\text {phase }}$ always positive governed by the positive component of current. From Fig. 5.d, it is observed that with the increase of flux the motor operates at more leading power factors.

flux the non-operating region of the motor decreases. From Fig. 6.b, for lower values of flux the torque component of current $\mathrm{i}_{\text {qstar }}$ is dominating and the $\mathrm{i}_{\text {phase }}$ is obviously governed by $\mathrm{i}_{\mathrm{qstar}}$ which is depicted in Fig. 6.c. From Fig. 6.d, for lower values of flux the non-operating region of the motor increases and almost matching with that of $\delta$ variation. From Fig. 6.d, it is observed that with the increase of flux the motor operates at more leading power factors.

\section{CONCLUSIONS}

In this paper a project stratagem for a nonlinear vector controller fed BLDC motor usingthe torque angle $(\delta)$ control and internal power factor angle $(\psi)$ control has been presented. It is found that, there is an extensive range of dynamic performance with the use of $\delta$ and $\psi$ controls. This also tends to provide great flexibility of getting the required power factor from lagging to leading (or vice versa) through unity. We can also get the particular case of FOCby choosing $\psi$ to be zero. This results aperfect decoupling nature between armature and field of the BLDC motor such as DC motor. This independent controlimproves the dynamic performance of the system. It is also observed that, from Fig. 4.d with $\delta$ variation the armature phase current $\mathrm{i}_{\text {phase }}$ is governed by the torque component of current $\mathrm{i}_{\text {qstar }}$ and from Fig. 4.d with $\psi$ variation the armature phase current $i_{\text {phase }}$ is governed by the flux component of current $i_{\text {dstar }}$.

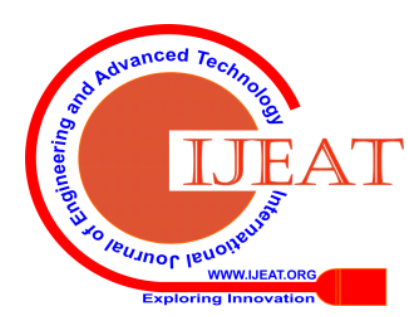




\section{APPENDIX}

Machine Ratings and Parameters of Brushless DC Motor (BLDC Motor):

Ratings of Brushless DC Motor: Rated Voltage $=400 \mathrm{~V}$, Rated Current $=2.17 \mathrm{~A}$, Rated Speed $=1500 \mathrm{rpm}$, No. of poles $=4$, Rated power: $1.2 / 1.5 \mathrm{KW}$, power factor $=0.8 / 1.0$ $, I=0.048 \mathrm{Kg} . \mathrm{m}^{2}, D=0.0048 \mathrm{~N} . \mathrm{m} / \mathrm{rad} / \mathrm{sec}$.

\section{REFERENCES}

1.Jianwen Shao, Member IEEE, Dennis Nolan, MaximeTeissier and David Swanson, "A Novel Microcontroller Based Sensorless Brushless DC (BLDC) Motor Drive for Automative Fuel Pumps", IEEE Transactions on Industry Applications, vol. 39, no.6, pp. 1734-1740, 2003.

2. July Singh. M.S, "Analysis of the speed control of BLDC motor drive using sensors", International Journal of Engineering Research and Applications, ISSN: 2248-9622, vol. 3, Issue 3, no.1, pp. 2868-2884, 2012.

3. Junxicai, Chunyan Lai, Narayan C. Kar, "Modeling and Analysis of Torque Ripple in a Brushless DC Motor Considering Spatial Harmonics". IEEE $30^{\text {th }}$ Canadian conference on Electrical and Computer Engineering (CCECE), 2017.

4. DevendraPotnuru, Kumar, Karlapudi Alice Mary, SaiBabu, (in press). "Design and implementation methodology for rapid control prototyping of closed loop speed control for BLDC motor.Journal of Electrical Systems and Information Technology", (Elsevier Journal publication), available online at www.sciencedirect.com

5. FeriYusivar, Hade SaputraHaslim, YasilFarabi, KusnanNuryadi, "New Control Scheme for Combined Regenerative and Mechanical Brakes in Electrical Vehicles", International Journal of Technology, 1:44-52, ISSN 2086-9614, 2015.

6. Ramana, Surya Kalavathi, Alice Mary and Dinesh Gowri Kumar, "Design methodology for field orientation control of a non-linear vector controlled sinusoidal permanent magnet ac motor", ARPN journal Engineering and technology, vol. 10, no.5, pp. 2159-2166, 2015.

7.Ramana, Alice mary, Kalavathi, "State Feedback Linearization of a Nonlinear Permanent Magnet Synchronous Motor Drive".Indonesian Journal of Electrical Engineering and Computer Science, vol. 1, no.3, pp. 1-6, 2016.

8.Merzoug M.S, Benalla and Louze, "Nonlinear Control of Permanent Magnet Synchronous Generators (PMSG) using Feedback Linearization.Revue des Energies Renouvelables”, vol. 14, no.2, pp. 357 $367,2011$.

9. R. Krishnan, "Electric motor drives-Modelling analysis and control", prentice hall, 2001.

10. P. C. Krause," Analysis of electric machinery”, McGraw-Hill, 1987.

\section{Authors Profile}

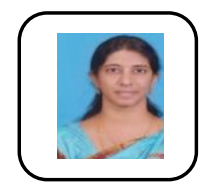

Mrs. T. V. Subhashini, is currently working as an assistant Professor in the Department of Electrical and Electronics Engineering at ANITS, Sangivalasa, BheemiliMandal, Visakhapatnam, A.P, India. She received $\mathrm{BE}$ degree in Electrical and Electronics Engineering from ANITS, Sangivalasa, BheemiliMandal, Visakhapatnam, A.P, India. She completed M.Tech in Power Electronics and industrial Drives from JNTU Hyderabad, A.P, India and pursuing Ph.D in JNTUK, Kakinada. She has 10 years of teaching experience. Her research interests include Control System Applications to Power Electronics and Machine Drives. Her publications are in UGC approved journals. She is an Associate member in "The Institution of Engineers (India)".

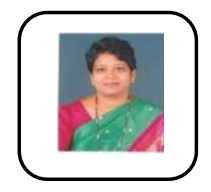

Dr. Karlapudy Alice Mary (F'60) is currently working as a Professor in EEE Dept. GEC, Gudlavalleru, A.P. She received BE degree in Electrical Power Engineering from Govt. B.D.T College of Engineering \& Technology Davangere, Karnataka, India, ME in Power Electronics and Drives from University of Roorkee U.P. India and Ph.D from IIT, KGP, W.B. India. She has 37 years of teaching experience, worked at different levels as Director of outreach program and Principal of three various engineering institutions and published around 75 papers. Her research interests include Control System Applications to Power Electronics and Machine Drives and produced 3 Ph.Ds.

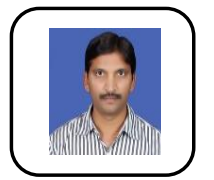

Dr. K. Ravindra is currently working as an Associate Professor in EEE Dept., JNTUK, Kakinada, A.P, India. He has 14 years of teaching experience and published 6 international journals, 1 national journal. He has attended for 11 international conferences. His research interest includes Distribution Generation, Soft computing techniques, power converters and renewable energy systems. 